\title{
Formation and Structure of Nanocrystalline Al-Mm-Ni-Cu Alloys
}

\author{
J. Latuch, M. Krasnowski and B. Ciesielska \\ Faculty of Materials Science and Engineering, Warsaw University of Technology \\ Woloska 141, 02-507 Warszawa, Poland
}

\begin{abstract}
This paper reports the results of a short investigation on the effect of $\mathrm{Cu}$ additions upon the nanocrystallization behaviour of an $\mathrm{Al}-\mathrm{Mm}-\mathrm{Ni}$ alloy. 2 at. $\% \mathrm{Cu}$ added to a base alloy of $\mathrm{Al}_{85} \mathrm{Mm}_{10} \mathrm{Ni}_{5}$ alloy by substitution for $\mathrm{Mm}$ (mischmetal). The control of cooling rate did not cause the formation of nanocrystals of fcc-Al phase. The nanocrystalline structure fcc-Al + amorphous phase in quarternary alloy was obtained by isothermal annealing and continuous heating method, but the last technique is more effective. The volume fraction, lattice parameter, and size of Al-phase were calculated.
\end{abstract}

PACS numbers: 61.43.Dq, 81.05.Kf, 81.70.Pg

\section{Introduction}

Increasing demand for high performance engineering components continuously drives the development of new advanced materials. Amorphous and nanocrystalline alloys are examples of such materials. For example, Al-based amorphous alloys containing rare earths (RE) and transition metals (TM) [1] have been reported to exhibit tensile fracture strengths in excess of $1 \mathrm{GPa}$ [2], about twice higher than the highest value for conventional crystalline Al-alloys. Work on these materials has found a further stimulus from the finding that partially crystallised alloys, also termed nanocomposites since they contain crystals of small size, may display outstanding mechanical properties [3].

High cooling rates are needed for amorphization of Al-rich alloys due to the tendency of crystal phases, specifically Al. This can be exploited for obtaining partially crystallised materials directly from melt quenching [4]. Alternatively the glass is annealed to induce devitrification [5]. In this investigation the effect of $\mathrm{Cu}$ additions on the thermal stability of the amorphous phase and the morphology of $\mathrm{Al}$ nanocrystals that form during primary crystallization has been studied by 
adding 2 at.\% $\mathrm{Cu}$ to a base alloy of $\mathrm{Al}_{85} \mathrm{Mm}_{10} \mathrm{Ni}_{5}$ by substitution for $\mathrm{Mm}$. The replacement of rare earth elements by $\mathrm{Mm}$ reduces the cost of investigated materials because $\mathrm{Mm}$ is cheaper about 10 times than for example yttrium.

\section{Experimental methods}

Ingots of ternary $\mathrm{Al}_{85} \mathrm{Mm}_{10} \mathrm{Ni}_{5}$ and quaternary $\mathrm{Al}_{85} \mathrm{Mm}_{8} \mathrm{Ni}_{5} \mathrm{Cu}_{2}$ alloys were prepared from purity elements by arc melting in an argon atmosphere. The $\mathrm{Mm}$ metal is composed of 50.3 at.\%Ce, 43.5 at.\% La, 5.9 at.\%Pr, and 0.3 at.\% Nd. During melt spinning, the melt was ejected from the crucible on to a rotating copper wheel with peripheral speeds of from 25 to $40 \mathrm{~m} \mathrm{~s}^{-1}$. By this technique, it is possible to quench the melt with a rate of $10^{5}-10^{6} \mathrm{~K} \mathrm{~s}^{-1}$. The resulting ribbons were typically $2 \mathrm{~mm}$ wide and $28-40 \mu \mathrm{m}$ thick. The microstructures of the ribbons were studied by X-ray diffraction (XRD) using $\mathrm{Cu} K_{\alpha}$ radiation and by transmission electron microscopy (TEM). Crystallization temperatures and heat of crystallization were calculated by differential scanning calorimetry (DSC) working in continuous and isothermal heating modes. The volume fractions $V_{\mathrm{f}}$ of $\alpha$-Al nanocrystals in ribbons was estimated by the method described by Inoue et al. [6]. Thin film specimens were prepared by an ion beam milling technique.

\section{Results and discussion}

Figure 1a,b illustrates XRD traces obtained from the as-melt spun alloys $\mathrm{Al}_{85} \mathrm{Mm}_{10} \mathrm{Ni}_{5}$ and $\mathrm{Al}_{85} \mathrm{Mm}_{8} \mathrm{Ni}_{5} \mathrm{Cu}_{2}$. All traces show the broad "diffuse" peak which is typical of amorphous alloys. It has been reported that selected quenching rates lead to the formation of different amount of volume fraction of nanoscale $\mathrm{Al}$ crystallites in an amorphous matrix of Al-RE-TM alloys, e.g. [1, 5]. In the investigated ternary alloy decreasing the cooling rate (rotational speed) does not change the amorphous structure. It is very interesting that bending ductility changes from fully ductile to brittle. The same trend was observed for quaternary studied alloy.

One method to assess the glass forming ability of alloys is to use DSC to measure the temperature at which the amorphous phase starts to crystallise. For fully amorphous materials there should be a clear glass transition prior to the first crystallization peak, however, it is well known that amorphous Al alloys with low solute contents do not exhibit a glass transition. In these alloys primary crystallization occurs at pre-existing nuclei (which are still not clearly characterised) and so it is not possible to accurately identify the crystallization onset temperature. In this work the peak temperatures are used for comparison instead. Figure 2 shows typical DSC traces for the as-melt spun $\mathrm{Al}_{85} \mathrm{Mm}_{10} \mathrm{Ni}_{5}$ and $\mathrm{Al}_{85} \mathrm{Mm}_{8} \mathrm{Ni}_{5} \mathrm{Cu}_{2}$ specimens using continuous heating at $40^{\circ} \mathrm{C} / \mathrm{min}$. The alloy without $\mathrm{Cu}$ atoms exhibits two exothermic effects, the first peak with a peak temperature of $331^{\circ} \mathrm{C}$ and the second with a peak temperature of $407^{\circ} \mathrm{C} . \mathrm{Al}_{85} \mathrm{Mm}_{8} \mathrm{Ni}_{5} \mathrm{Cu}_{2}$ shows a broad first 

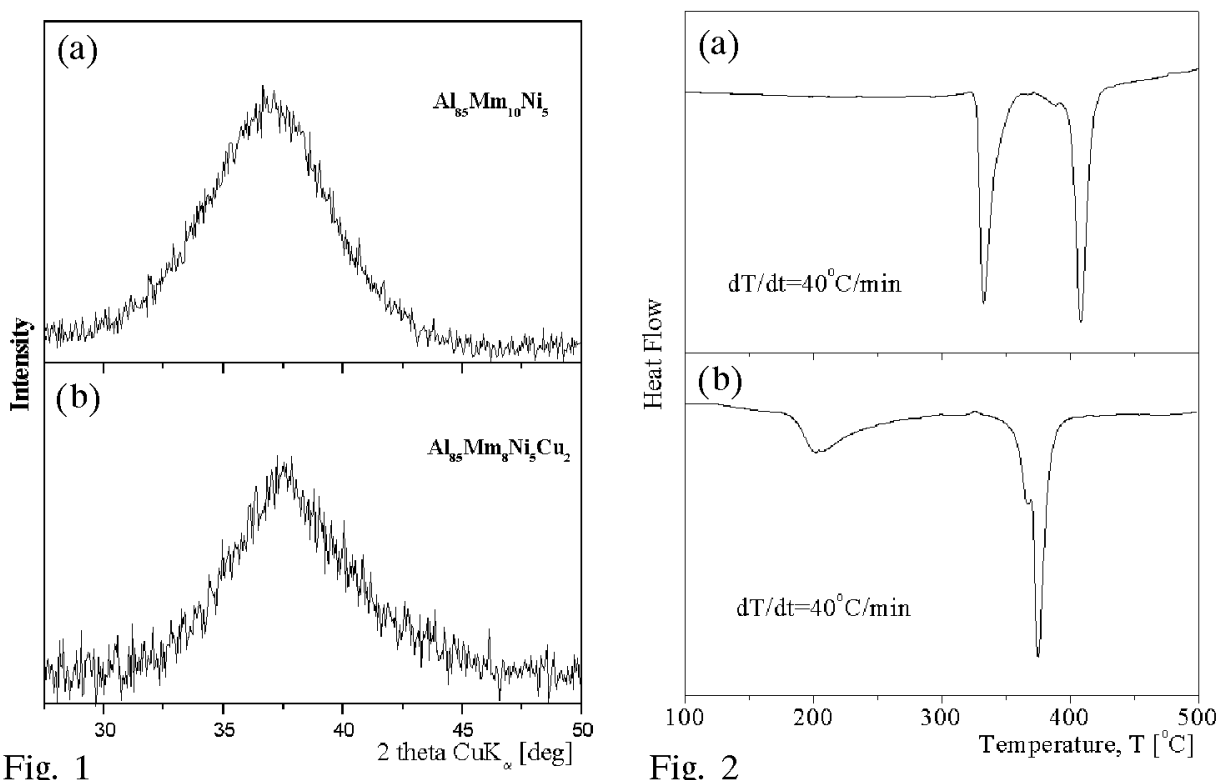

Fig. 1. XRD patterns of as-melt-spun alloys: (a) $\mathrm{Al}_{85} \mathrm{Mm}_{10} \mathrm{Ni}_{5}$; (b) $\mathrm{Al}_{85} \mathrm{Mm}_{8} \mathrm{Ni}_{5} \mathrm{Cu}_{2}$.

Fig. 2. DSC traces of as-melt-spun alloys: (a) $\mathrm{Al}_{85} \mathrm{Mm}_{10} \mathrm{Ni}_{5}$; (b) $\mathrm{Al}_{85} \mathrm{Mm}_{8} \mathrm{Ni}_{5} \mathrm{Cu}_{2}$.

peak at $176^{\circ} \mathrm{C}$, which was the lower temperature of the two alloys, followed by peaks at 366 and $375^{\circ} \mathrm{C}$. Comparison of the peak temperatures for the first peaks indicates that 2 at.\% substitution $\mathrm{Mm}$ by $\mathrm{Cu}$ decreases the thermal stability of the amorphous phase.

The process of nanocrystallization of investigated alloys was also done by the indirect method, i.e. by isothermal annealing of initially fully amorphous alloys at temperatures below the temperature of the onset of crystallization. The annealed samples retain the amorphous state and change to mixed structures (fcc-Al+ $\mathrm{Al}_{11}(\mathrm{Ce}, \mathrm{La})_{3}+\mathrm{Al}_{3} \mathrm{Ni}[7], \mathrm{fcc}-\mathrm{Al}+$ amorphous) for the alloy $\mathrm{Al}_{85} \mathrm{Mm}_{10} \mathrm{Ni}_{5}$ and $\mathrm{Al}_{85} \mathrm{Mm}_{8} \mathrm{Ni}_{5} \mathrm{Cu}_{2}$, respectively. Only the isothermal annealed quaternary alloy was in a ductile state. The XRD pattern shown in Fig. 3 displays very small peaks indicating the presence of some $\mathrm{Al}$ nanocrystals in the as-spun ribbon. This was confirmed by microstructural examination using dark field TEM. Very small spherical nanocrystals about $5-7 \mathrm{~nm}$ were visible. The maximum value of $V_{\mathrm{f}}(\sim 10 \%)$ was calculated for samples annealed at $160^{\circ} \mathrm{C}$ for $20 \mathrm{~min}$.

The most effective method of nanocrystallization of $\mathrm{Al}_{85} \mathrm{Mm}_{8} \mathrm{Ni}_{5} \mathrm{Cu}_{2}$ alloy was isochronally heated to the temperature of $310^{\circ} \mathrm{C}$ (the end temperature of the first DSC peak). It is confirmed by XRD and TEM that the first exothermic peak in this alloy is associated with the formation of fcc-Al phase (Fig. 3). The remaining sharp exothermic peaks correspond to the precipitation of $\mathrm{Al}$ and intermetallic compounds. The calculated lattice parameter of Al-phase is $0.405 \mathrm{~nm}$. This value 


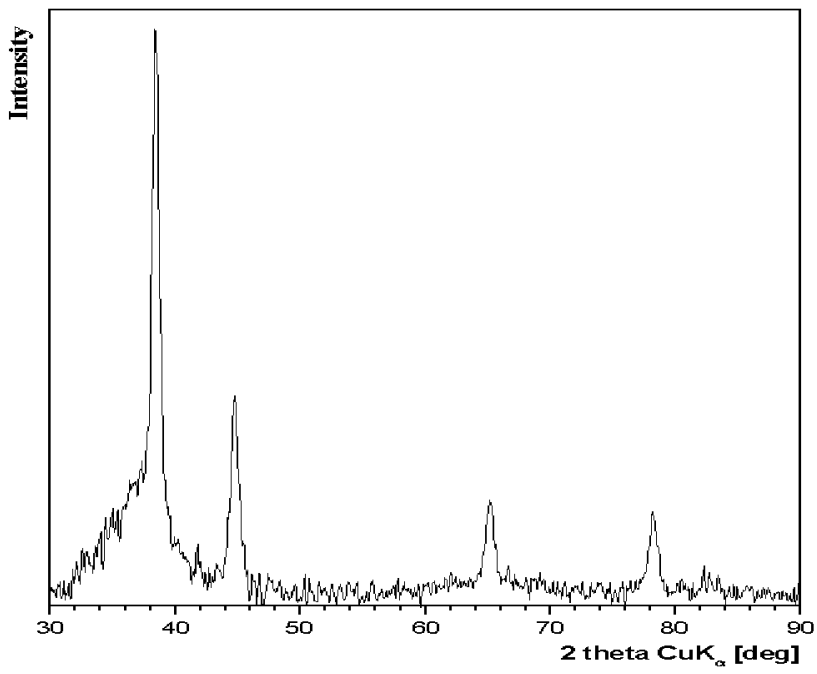

Fig. 3. XRD pattern of $\mathrm{Al}_{85} \mathrm{Mm}_{8} \mathrm{Ni}_{5} \mathrm{Cu}_{2}$ alloy continuously heated up to $310^{\circ} \mathrm{C}$.

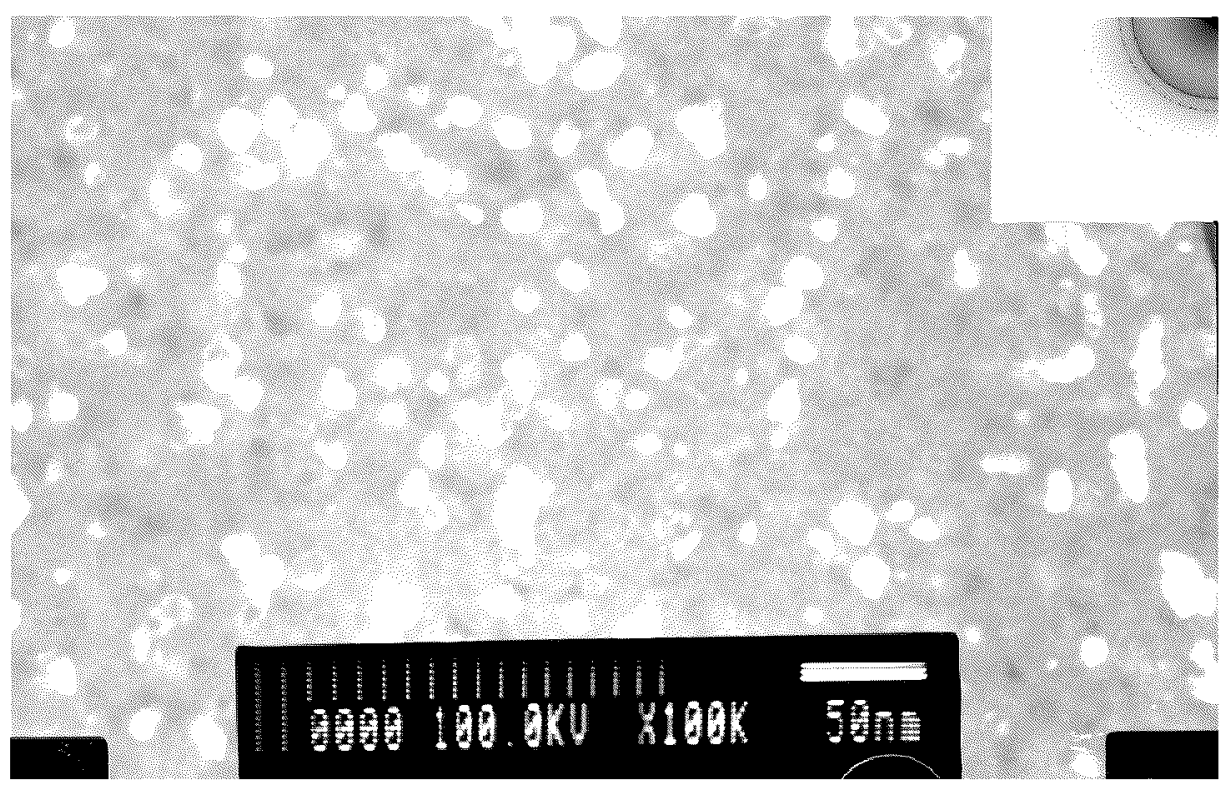

Fig. 4. Dark field images with selected-area electron diffraction pattern $\mathrm{Al}_{85} \mathrm{Mm}_{8} \mathrm{Ni}_{5} \mathrm{Cu}_{2}$ continuously heated up to $310^{\circ} \mathrm{C}$.

is larger than that of pure Al metal $(0.4047 \mathrm{~nm})$. The Al phase seems to be a supersaturated solid solution containing rare earth metals. The microstructure (Fig. 4) generally consists of a random distribution of about $10-20 \mathrm{~nm}$ fcc-Al 
nanocrystals embedded in an amorphous phase. The smallest nanocrystals are spherical in shape, whereas the larger nanocrystals are slightly dendritic. The maximum value of $V_{\mathrm{f}}$, for which this alloy is still in the ductile state, reaches a relatively high level, i.e. $35 \%$.

\section{Conclusion}

In this work the effect of addition of $\mathrm{Cu}$ upon the thermal stability of the amorphous phase and the formation of $\mathrm{Al}$ nanocrystals during primary crystallization has been studied by adding 2 at.\% $\mathrm{Cu}$ to a base alloy of $\mathrm{Al}_{85} \mathrm{Mm}_{10} \mathrm{Ni}_{5}$ by substitution for $\mathrm{Mm}$ to the form of $\mathrm{Al}_{85} \mathrm{Mm}_{8} \mathrm{Ni}_{5} \mathrm{Cu}_{2}$. The substitution of $\mathrm{Cu}$ for $\mathrm{Mm}$ was found to decrease the thermal stability of the amorphous phase. From three used nanocrystallization methods (rapid solidification, isothermal annealing, continuous heating) the last one was more effective. Explanation of the influence of $\mathrm{Cu}$ atoms in the process of nanocrystallization of $\mathrm{Al}-\mathrm{Mm}-\mathrm{Ni}$ alloys requires nanometre scale chemical analysis of the local partitioning behaviour of the $\mathrm{Cu}$.

\section{Acknowledgments}

The financial support from the State Committee for Scientific Research under project KBN No. PBZ/KBN/13/T08/99/21 and EU Project No. HPRN-CT-2000-00038 are gratefully acknowledged. The authors also like to thank TREIBACHER AUERMET Produktionsges. m.b.H for Mm delivery.

\section{References}

[1] A. Inoue, Prog. Mater. Sci. 43, 365 (1998).

[2] A. Inoue, M. Yamamoto, H.M. Kimura, T. Masumoto, J. Mater. Sci. Lett. 6, 194 (1987)

[3] Y.H. Kim, A. Inoue, T. Masumoto, Mater. Trans. JIM 31, 747 (1990).

[4] Z.C. Zhong, A.L. Greer, Int. J. Non-Equilibrium Process 11, 35 (1998).

[5] J. Latuch, A. Kokoszkiewicz, H. Matyja, Mater. Sci. Eng. A 226-228, 809 (1997).

[6] A. Inoue, H. Tomioka, T. Masumoto, J. Mater. Sci. 18, 153 (1983).

[7] K. Ohtera, A. Inoue, T. Terebayashi, H. Nagahama, T. Masumoto, Mater. Trans. JIM 33, 775 (1992). 